\title{
A study of the possible role of prostaglandins in decidualization using a nonsurgical method for the instillation of fluids into the rat uterine lumen
}

\author{
J. A. Tobert* \\ Department of Pharmacology, The School of Pharmacy, University of London, \\ 29/39, Brunswick Square, London WCIN 1AX, U.K.
}

The decidual cell reaction (DCR) is thought to be induced by some substance released when the epithelium is exposed to the implanting blastocyst or an artificial stimulus, but the identity of the putative transmitter is obscure. It was at one time believed to be histamine (Shelesnyak, 1957), but this theory has been questioned (De Feo, 1967; Tachi, Tachi \& Lindner, 1970; Finn, 1971). The prostaglandins (PGs), which have yet to be investigated in this context, possess a number of properties which make them plausible contenders for the transmitter role (Tobert, 1975). For example, they are released from tissues by trauma and other decidual stimuli (Ferreira \& Vane, 1974) and may, through their action on cyclic nucleotide levels, be involved in the control of cell differentiation and proliferation (McMahon, 1974; Jimenez de Asua, Clingan \& Rudland, 1975). The effects of PGE-2 and PGF-2 $\alpha$, their precursor arachidonic acid, and an inhibitor of PG synthesis, indomethacin, on the DCR of rats were therefore studied.

The lumen of the rat uterus is usually approached via an abdominal incision. The vaginal route has been used to insert an IUD (Wrenn, Wood \& Bitman, 1968), for egg transfer (Bennett \& Vickery, 1970), or to apply drugs to the endometrium (Barker, 1967) but, as far as I know, none of the numerous studies on the DCR in the rat has used this approach. The transcervical route used in the present study avoids the trauma and expenditure of time associated with laparotomy.

\section{Materials and methods}

Virgin Wistar rats, weighing 180-300 g, were kept in a $14 \mathrm{hr}$ light regimen (05.00-19.00 hours). Pseudopregnancy was induced during oestrus by vagino-cervical vibration (De Feo, 1966) for at least $1 \mathrm{~min}$. The last day of oestrus was designated Day 0.

Experiment 1. The DCR was produced by intraluminal instillation of olive oil, which produces massive decidualization (Finn \& Keen, 1963), and is considered to be more physiological in its action than the commonly used uterine trauma (Finn, 1971). The oil $(50 \mu \mathrm{l})$ was injected randomly into either horn at 17.00-20.00 hours on Days 3 or 4 using a 22-gauge, 11-cm steel cannula connected to a 1-ml plastic syringe. The animal was anaesthetized with ether and the cannula inserted through the cervical canal after visualization of the cervix through an otoscope. The depth of penetration was limited to $10 \mathrm{~mm}$ by a small piece of plastic tubing pushed over the cannula, which was slowly withdrawn 15-20 sec after the injection. Indomethacin was dissolved in $0.5 \%(\mathrm{w} / \mathrm{v})$ sodium bicarbonate to give a $2.5 \mathrm{mg} / \mathrm{ml}$ solution. A single dose $(5 \mathrm{mg} / \mathrm{kg}$ ) was given s.c. $2 \mathrm{hr}$ before the Day 3 stimulus, or $2 \mathrm{hr}$ before or $8 \mathrm{hr}$ after the Day 4 stimulus. Weight-matched controls received a s.c. saline injection at the same time. At the time of oil instillation it was not known which animals had received, or would receive, indomethacin.

Experiment 2. For injection of fiuids simultaneously into each uterine horn, a double-barrelled injection system was constructed from two syringes and cannulae of the type used in Exp. 1. The syringe barrels were cemented together and the cannulae splinted with balsa wood to make the distal ends touch. The splint terminated $15 \mathrm{~mm}$ from the orifices, so that, when gentle pressure was applied

\footnotetext{
* Present address: Laboratory of Human Reproduction and Reproductive Biology, Harvard Medical School, Boston, Massachusetts 02115, U.S.A.
} 
at the cervix, the tips splayed out slightly and each cannula penetrated the corresponding os cervix. A $10 \mathrm{~mm}$ stop was placed on one cannula as before. Experiments with dyes confirmed that solutions could be injected into the right or left horn at will and that mixing of the two solutions does not occur. A plastic bar was cemented across the handles of the syringe plungers to permit simultaneous injection of equal volumes of fluid at the same speed and thus eliminate a possible cause of variation in the magnitude of the DCR. The rats were anaesthetized as before and at 17.00-20.00 hours on Day $450 \mu \mathrm{g}$ PGE-2 (free acid) (8 rats), $50 \mu \mathrm{g}$ PGF-2 $\alpha$ (10 rats) or $200 \mu \mathrm{g}$ arachidonic acid (6 rats) were instilled into one uterine horn. The same volume $(50 \mu \mathrm{l})$ of the corresponding vehicle $(0 \cdot 1$ M-tris buffer, $\mathrm{pH} 7 \cdot 0$, for the PGs and $5 \%$ sodium bicarbonate, $\mathrm{pH} 8 \cdot 2$, for arachidonic acid) was injected into the other horn. Test and control solutions were distributed equally between the left and right horns. The cannulae were slowly withdrawn after 15-20 sec and the cervix was smeared with silicone grease in an attempt to occlude temporarily the cervical canals.

All the rats were killed by stunning and cervical dislocation at 09.00-12.00 hours on Day 9. The uterine horns were transected just above the cervix, dissected free from fat and weighed separately. The magnitude of the DCR was assumed to be proportional to the weight of the horn (De Feo, 1967; Finn, 1971).

\section{Results and conclusions}

When indomethacin was given $2 \mathrm{hr}$ before the Day 3 stimulus, there was no significant differer. in the mean weight ( \pm S.E.M.) of the decidualized horn $(1.30 \pm 0.16 \mathrm{~g}, \mathrm{~N}=6)$ compared wit controls $(1.02 \pm 0.18 \mathrm{~g}, \mathrm{~N}=8)$. Indomethacin significantly reduced mean horn weight when $\mathrm{g}$ either $2 \mathrm{hr}$ before $(1.39 \pm 0.09 \mathrm{~g}, \mathrm{~N}=8$, versus $2.02 \pm 0.11 \mathrm{~g}, \mathrm{~N}=8 ; P<0.001$ by Student's $t$ test $)$ or 8 hr after $(1.59 \pm 0.09 \mathrm{~g}, \mathrm{~N}=10$, versus $2 \cdot 11 \pm 0.13 \mathrm{~g}, \mathrm{~N}=7 ; P<0.01)$ the oil stimulus on Day 4 .

The most likely site of the DCR-inhibiting action of indomethacin is the endometrium. The drug may change the hormonal milieu in a way unfavourable for the development of deciduomata, but it seems improbable that a single dose would have a significant effect, and there is no evidence in the literature to support such an action. Since all the therapeutic actions of indomethacin can be attributed to inhibition of prostaglandin synthesis (Flower \& Vane, 1974), and since a single, relatively low, dose which produces no obvious toxic effects was used, these results suggest a role for PGs in the decidualization process, at least from Day 4 when maximum sensitivity to a decidual stimulus is acquired (De Feo, 1967) and implantation normally commences.

In Exp. 2 the aqueous vehicles produced decidual responses approximately half those obtained with oil, which is consistent with the results of Finn \& Keen (1963). None of the drugs augmented or reduced the response. Although some investigators (e.g. Webb, 1975) have regarded the inactivity of intraluminally injected substances as evidence against their involvement in the decidualization process, negative results may not be conclusive. Conner \& Miller (1973) showed that in the oestrogentreated spayed rat lipid-soluble drugs equilibrate rapidly between blood and uterine fluid, and when barbitone, for example, was injected into the uterine lumen after ligation of the cervix, half of it was lost within $10 \mathrm{~min}$. The uterine epithelium of the pseudopregnant rat is also capable of pinocytosis (Enders \& Nelson, 1973; Parr \& Parr, 1974). It is therefore likely that PGs and arachidonic acid are rapidly removed from the uterine lumen. The resulting transient elevation of endometrial PG levels may not constitute a realistic test of the deciduogenic capacity of the PGs, particularly as the inhibition of the DCR when indomethacin was given $8 \mathrm{hr}$ after the oil suggests a prolonged synthesis of PG after the decidual stimulus.

Indomethacin and the prostaglandins were gifts from Merck, Sharp and Dohme and Upjohn, respectively.

\section{References}

BARKER, K.L. (1967) Co-factor induced synthesis of D-glucose-6-phosphate: NADP oxidoreductase in the uterus. Endocrinology 81, 791-797.

BENNETT, J.P. \& VICKERY, B.H. (1970) Rats and mice. In Reproduction and Breeding Techninues for I.abor- atory Animals, pp. 299-315. Ed. E. S. E. Hafez. Lea \& Febiger, Philadelphia.

Conner, E.A. \& Miller, J.W. (1973) The distribution of selected substances into rat luminal fluid. J. Pharm. exp. Ther. 184, 291-298. 
DE FEo, V.J. (1966) Vaginal-cervical vibration: a simple and effective method for the induction of pseudopregnancy in the rat. Endocrinology 79, 440-442.

DE Feo, V.J. (1967) Decidualization. In Cellular Biology of the Uterus, pp. 191-290. Ed. R. M. Wynn. Appleton-Century-Crofts, New York.

Enders, A.C. \& Nelson, D.M. (1973) Pinocytic activity of the uterus of the rat. Am. J. Anat. 138, 277-300.

Ferreira, S.H. \& Vane, J.R. (1974) Aspirin and prostaglandins. In Prostaglandins, Vol. 2, pp. 1-47. Ed. P. W. Ramwell. Plenum Press, London.

FInN, C.A. (1971) The biology of decidual cells. Adv. Reprod. Physiol. 5, 1-26.

FInN, C.A. \& KeEN, P.M. (1963) The induction of deciduomata in the rat. $J$. Embryol. exp. Morph. 11, 673-682.

FlOWER, R.J. \& VANE, J.R. (1974) Inhibition of prostaglandin biosynthesis. Biochem. Pharmac. 23, 1439 1450.

Jimenez de Asua, L., Clingan, D. \& Rudland, P.S. (1975) Initiation of cell proliferation in cultured mouse fibroblasts by prostaglandin $F_{2 \alpha}$. Proc. natr. Acad. Sci. U.S.A. 72, 2724-2728.

MCMAHON, D. (1974) Chemical messengers in development: a hypothesis. Science, N.Y. 185, 1012-1021.

PARr, E. \& PARr, M. (1974) Uterine luminal epithelium: protrusions mediate endocytosis, not apocrine secretion, in the rat. Biol. Reprod. 11, 220-233.

SHELESNYAK, M.C. (1957) Some experimental studies on the mechanism of ova-implantation in the rat. Recent Prog. Horm. Res. 13, 269-322.

TACHI, C., TACHI, S. \& LindneR, H.R. (1970) Action of antihistamines on the endometrium and the histamine theory of decidual induction. $J$. Reprod. Fert. 23, 169-172.

TOBERT, J.A. (1975) The Pharmacology of Intrauterine Copper. Ph.D. thesis, University of London.

WEBB, F.T.G. (1975) The inability of dibutyryl adenosine 3',5'-monophosphate to induce the decidual cell reaction in intact pseudopregnant mice. $J$. Reprod. Fert. 42, 187-188.

WrenN, R.T., Wood, J.R. \& Bitman, J. (1968) A new technique for introducing IUDs into rat uteri. J. Reprod. Fert. 16, 515-517.

Received 23 January 1976 